\title{
Management of intractable chronic cough during awake craniotomy: illustrative case
}

\author{
Yena Kang, BA, ${ }^{1}$ Robbi A. Kupfer, MD, ${ }^{2}$ Elizabeth Ford-Baldner, MA, ${ }^{3}$ Karen J. Kluin, MS, ${ }^{3,4}$ Shawn L. Hervey-Jumper, MD, ${ }^{5}$ and \\ Robert J. Morrison, $M D^{2}$ \\ ${ }^{1}$ University of Michigan Medical School, University of Michigan, Ann Arbor, Michigan; Departments of ${ }^{2}$ Otolaryngology-Head and Neck Surgery, ${ }^{3}$ Speech-Language Pathology, \\ and ${ }^{4}$ Neurology, University of Michigan, Ann Arbor, Michigan; and ${ }^{5}$ Department of Neurological Surgery, University of California San Francisco, San Francisco, California
}

BACKGROUND Chronic cough is a common but challenging clinical condition that can adversely affect the safety of awake surgical endeavors such as awake craniotomy (AC). This case lesson highlighted a patient with severe refractory chronic cough undergoing AC for resection of a recurrent left frontal, insula, anterior temporal anaplastic ependymoma of the eloquent cortex.

OBSERVATIONS The patient was successfully managed using a multifaceted medical treatment regimen combined with preoperative and intraoperative cough suppression therapy with a speech-language pathologist. The patient coughed only once intraoperatively and had a positive outcome.

LESSONS Chronic cough is often multifactorial and requires a multifaceted treatment approach. Despite this challenge, select patients can successfully be navigated through $\mathrm{AC}$ with appropriate treatment for their condition. A review of neurogenic cough and modern treatments, which were used in this patient and would be helpful to neurologists or neurosurgeons, are also discussed.

https://thejns.org/doi/abs/10.3171/CASE21480

KEYWORDS awake craniotomy; chronic cough; neurogenic cough; cough suppression therapy; speech pathology

An awake craniotomy $(A C)$ is a neurosurgical operation performed in the same manner as a conventional craniotomy but with the patient awake during the procedure. This is often the preferred surgery to remove brain tumors close to or involving functionally important or eloquent regions of the brain. ${ }^{1}$ Chronic cough is a disease entity of persistent cough with severe impacts on quality of life. ${ }^{2} \mathrm{~A}$ patient with chronic cough may experience difficulty lying flat and being able to participate in speech and language tasks required during the awake procedure. This case report highlights successful management of chronic cough using a multifaceted treatment approach. This approach allowed the patient to participate in language mapping studies and monitoring of motor speech and language skills during an $\mathrm{AC}$ for resection of a brain tumor in his language-dominant hemisphere.

\section{Illustrative Case}

Clinical Presentation and Prior Investigations

A 46-year-old right-handed man with the left hemisphere dominant for language per functional magnetic resonance imaging presented with a 10-year history of chronic cough and left frontal anaplastic ependymoma status after two previous subtotal resections and adjuvant radiation. He subsequently developed seizures, and brain imaging revealed a lesion within the left frontal, anterior, and superior insula extending into the anterior temporal lobe concerning for recurrent anaplastic ependymoma (Fig. 1). Because of tumor location in the eloquent cortex, it was determined that the safest approach to biopsy and resection would be an $\mathrm{AC}$ with intraoperative language mapping studies and monitoring during the resection.

The patient's chronic cough occurred approximately once every hour and in bursts. It was worsened by talking, eating, and lying flat and could only be volitionally suppressed for a few seconds' duration. It was associated with a tickle sensation isolated over the larynx. He had previously consulted with allergists, pulmonologists, and otolaryngologists without a unifying diagnosis. He had failed trials of therapy with antihistamines, bronchodilators, mucolytics, antireflux medications, and cough suppressants. He had known positive test results to environmental allergies of pet dander and ragweed. He 


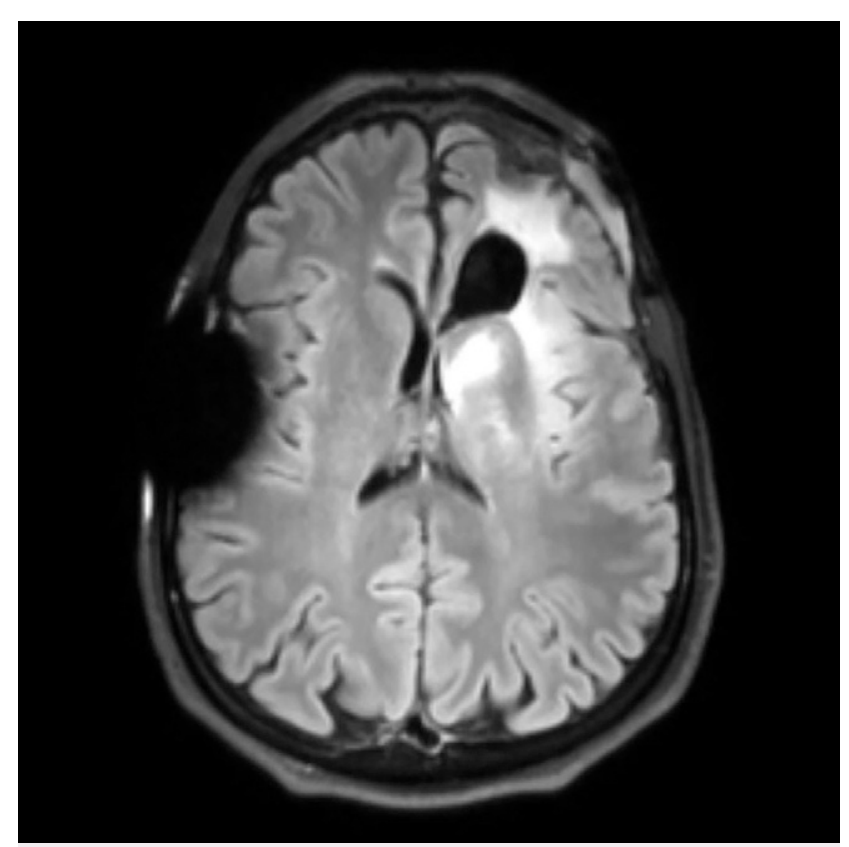

FIG. 1. Recurrent anaplastic ependymoma within the left frontal, anterior, and superior insula extending into the anterior temporal lobe, as seen on fluid-attenuated inversion recovery sequence cranial magnetic resonance imaging.

had no prior empirical evaluation for gastroesophageal reflux disease but endorsed symptoms of heartburn. He was evaluated in a multidisciplinary clinic by a laryngologist and speech-language pathologist before the operation. Examination demonstrated hyperreactivity of the larynx and intermittent suggestion of left vocal fold paresis. With cough-suppressive breathing techniques, he had increased control over the urge to cough, and full abduction of the vocal folds was noted. His chronic cough was felt to be multifactorial with a component of neurogenic cough. Pharmacological management was initiated, including a rapid gabapentin titration, codeine, aggressive reflux management, and a course of corticosteroids. Behavioral interventions for cough suppression were introduced, with nasal respiration, pursed lip exhalation, and modified breathing strategies being the most efficacious in mitigating episodes of cough. The patient was also seen by a speech-language pathologist for presurgical evaluation of his motor speech and language skills to determine participation in awake surgery, obtain baseline of speech and language skills, and identify language items the patient could perform flawlessly to minimize false-positive results and provide reliable language mapping intraoperatively. The purpose of intraoperative language mapping is to delineate cortical and subcortical sites of functional significance with respect to the lesion or epileptogenic focus, identify and preserve motor and language skills, and identify functional resection boundaries.

\section{Therapeutic Interventions}

The patient was accompanied by a speech-language pathologist intraoperatively. The patient displayed successful control of his cough during the mapping studies to allow multiple sites in the left inferior frontal, middle frontal, and superior frontal regions and in the left anterior temporal lobe/superior temporal gyrus to be stimulated as well as during the resection when his motor speech and language skills were monitored. There was only one instance of a cough, which was suppressed by nasal respiration under guidance by the speech pathologist. Pathology revealed recurrent anaplastic ependymoma. As a result of the patient's successful control of his cough during the procedure, the neurosurgeon was able to resect $90 \%$ of the recurrent tumor located in eloquent regions of the language-dominant hemisphere. Postoperatively, the patient experienced expected dysnomia and language problems, which gradually resolved over time. He continued to be managed with cough suppression treatment with speech pathology and gabapentin and codeine postoperatively, and he noted a $25 \%$ improvement in baseline cough frequency.

\section{Discussion \\ Observations}

Chronic cough is defined as a cough $>8$ weeks' duration that is typically dry or productive of minimal amounts of sputum. ${ }^{2}$ Chronic cough is most commonly a consequence of untreated rhinosinusitis (also termed upper airway cough syndrome), asthma, and gastroesophageal reflux disease. ${ }^{3}$ In approaching chronic cough, it is recommended that the patient initially undergo an algorithmic assessment that begins with objective testing and trials of therapy for these most common causes of cough. ${ }^{3}$ Patients should be trialed off contributing medications such as angiotensin-converting enzyme receptor inhibitors, and chest imaging should be performed if risk factors exist for malignancy. Focused investigation into rarer causes of cough should be tailored to the constellation of symptoms and any partial therapeutic benefit from prior treatments. Table 1 summarizes the potential etiologies of chronic cough and commonly used investigative studies.

\section{Neurogenic Cough}

Many patients experience refractory chronic cough that is recalcitrant to the aforementioned treatments or presents with exhaustive and essentially normal diagnostic evaluation. Emerging research suggests that refractory cough may arise as a result of sensitization of the vagal pathways that control cough. ${ }^{2,4,5}$ This disease entity is alternatively referred to as neurogenic cough, idiopathic or refractory cough, or cough hypersensitivity syndrome. It is commonly associated with a sensation of irritation localized to the throat and exacerbated by low-level physical and chemical stimuli, such as talking, swallowing, and odorants. Neurogenic cough is likely not a single disorder, and the neurological pathways underlying cough hyperresponsiveness require further investigation.

\section{Treatments of Neurogenic Cough}

A summary of treatments with some efficacy in neurogenic cough is presented in Table 2. Previous randomized controlled trials have demonstrated positive benefit to cough severity when speechlanguage pathology-based behavioral intervention has been employed. ${ }^{6,7}$ This treatment program, broadly termed cough suppression therapy, includes sessions on education, breathing exercises, cough suppression strategies, and counseling. Most often, two to four sessions are used to reduce cough reflex sensitivity, improve voluntary control over cough, reduce laryngeal irritation, and reduce laryngeal muscle tension. Patients can often use these techniques to supplement other medical treatment and can employ them when other treatments fail or as a primary treatment for chronic cough. 
TABLE 1. Common etiologies contributing to chronic cough

\begin{tabular}{lcc}
\hline \multicolumn{1}{c}{ Etiologies of Chronic Cough } & Investigative Studies & Treatments \\
\hline Obvious causes & Chest radiography & Smoking cessation \\
\cline { 2 - 3 } & $\begin{array}{c}\text { History of smoking, environmental exposures, } \\
\text { travel, or ACE-I }\end{array}$ & Trial off ACE-I for 6 wks \\
\hline Asthma & $\begin{array}{c}\text { Spirometry w/ bronchodilator } \pm \text { methacholine } \\
\text { challenge to assess for bronchial } \\
\text { honperreactivity }\end{array}$ & Short- or long-acting $\beta$ agonist inhaler \\
\cline { 2 - 3 } & Fraction exhaled nitric oxide test & Inhaled corticosteroid \\
\cline { 2 - 3 } & Sputum eosinophil count & Inhaled corticosteroid \\
\hline Gastroesophageal reflux disease & Ambulatory pH and/or impedence testing & Histamine type-2 receptor antagonist \\
\cline { 2 - 3 } & Esophageal endoscopy & Proton-pump inhibitor \\
\hline Rhinosinusitis & Esophageal fluoroscopy & Oral or intranasal antihistamine \\
\hline
\end{tabular}

ACE-I = angiotensin-converting enzyme inhibitor.

Although there are currently no medications approved by the U.S. Food and Drug Administration for neurogenic cough, neuromodulating agents, including tricyclic antidepressants and alpha-2-delta ligand antagonists, have been shown to have some efficacy in treatment of the disorder. $^{8}$ Gabapentin, amitriptyline, and pregabalin have all demonstrated improvement of chronic neurogenic cough on randomized controlled trials. $^{9-11}$ Limited lower-level evidence supports the use of antispasticity agents such as baclofen and opioids in palliative cases. ${ }^{12,13}$

Several emerging treatments exist for neurogenic cough. Injection of botulinum toxin into the intrinsic adductor muscles of the larynx performed by an otolaryngologist has been found to decrease severity of cough at 2-month follow-up and may serve to diminish the reinforcement of peripheral cough pathways. ${ }^{14}$ Simpson and colleagues have demonstrated efficacy of injections of steroids and a local anesthetic agent around the superior laryngeal nerve for mitigation of chronic cough. ${ }^{5}$ There is renewed interest in capsaicin desensitization treatment, which is hypothesized to reduce vagal c-fiber afferent activity by downregulation of transient receptor potential vanilloid-1 expression in upper aerodigestive mucosa. ${ }^{15} \mathrm{~A}$ novel antagonist to the P2X3 receptor, a key modulator of the activation of

TABLE 2. Commonly used treatments for neurogenic cough

\begin{tabular}{|c|c|c|}
\hline Category & Agent(s) & Proposed Mechanism of Action \\
\hline \multirow[t]{2}{*}{ Central neuromodulators } & Gabapentin \& pregabalin & $\begin{array}{l}\text { Alpha-2-delta ligand antagonist in central } \\
\text { cough center }\end{array}$ \\
\hline & Amitriptyline \& nortriptyline & $\begin{array}{l}\text { Serotonin reuptake inhibition in central cough } \\
\text { center }\end{array}$ \\
\hline \multirow[t]{4}{*}{ Central antitussives } & Codeine & \multirow{4}{*}{$\begin{array}{l}\mu \text {-opioid receptor stimulation in central cough } \\
\text { center }\end{array}$} \\
\hline & Dextromethorphan & \\
\hline & Morphine & \\
\hline & Tramadol & \\
\hline Cough suppression therapy & $\begin{array}{l}\text { Guided treatment sessions under direction of } \\
\text { speech-language pathologist }\end{array}$ & Reduction in cough-injury-cough cycle \\
\hline \multirow[t]{2}{*}{ Laryngeal botulinum toxin injections } & \multirow{2}{*}{$\begin{array}{l}\text { Injection of } 1-5 \text { units of botulinum toxin into } \\
\text { adductor muscles of vocal folds under } \\
\text { electromyographic guidance }\end{array}$} & Reduction in cough-injury-cough cycle \\
\hline & & $\begin{array}{c}\text { Direct analgesic effect on nociceptive cough } \\
\text { c-fibers }\end{array}$ \\
\hline Superior laryngeal nerve injections & $\begin{array}{l}\text { Injection of local anesthesia and/or } \\
\text { corticosteroid around superior laryngeal nerve }\end{array}$ & Disruption of cough signaling pathway \\
\hline Capsaicin desensitization & $\begin{array}{l}\text { Administration of gradually escalating doses of } \\
\text { aerosolized capsaicin }\end{array}$ & $\begin{array}{l}\text { Reduction in TRPV1 expression in } \\
\text { nociceptive cough c-fibers }\end{array}$ \\
\hline Peripheral cough receptor antagonist & Gefapixant & Peripheral P2X3 receptor antagonist \\
\hline
\end{tabular}

TRPV-1 = transient receptor potential vanilloid-1. 
sensory neurons central to the cough reflex, has demonstrated promise in randomized controlled trials but does not yet have regulatory approval. $^{16}$

\section{Lessons}

Chronic cough is a frustrating condition with significant qualityof-life impact that can complicate awake surgical endeavors such as AC. Collaboration with otolaryngologists and speech-language pathologists can often be beneficial in finding mitigation strategies and reducing severity and frequency of cough. Several emerging treatments for chronic neurogenic cough may be helpful for treating patients with this disorder.

\section{References}

1. Dziedzic T, Bernstein M. Awake craniotomy for brain tumor: indications, technique and benefits. Expert Rev Neurother. 2014;14(12):1405-1415.

2. Smith JA, Woodcock A. Chronic cough. N Engl J Med. 2016; 375(16):1544-1551.

3. Gibson P, Wang G, McGarvey L, Vertigan AE, Altman KW, Birring SS. Treatment of unexplained chronic cough: CHEST guideline and expert panel report. Chest. 2016;149(1):27-44.

4. Chung KF, McGarvey L, Mazzone SB. Chronic cough as a neuropathic disorder. Lancet Respir Med. 2013;1(5):414-422.

5. Simpson CB, Tibbetts KM, Loochtan MJ, Dominguez LM. Treatment of chronic neurogenic cough with in-office superior laryngeal nerve block. Laryngoscope. 2018;128(8):1898-1903.

6. Chamberlain S, Birring SS, Garrod R. Nonpharmacological interventions for refractory chronic cough patients: systematic review. Lung. 2014;192(1):75-85.

7. Vertigan AE, Theodoros DG, Gibson PG, Winkworth AL. Efficacy of speech pathology management for chronic cough: a randomised placebo controlled trial of treatment efficacy. Thorax. 2006;61(12):1065-1069.

8. Ryan NM, Vertigan AE, Birring SS. An update and systematic review on drug therapies for the treatment of refractory chronic cough. Expert Opin Pharmacother. 2018;19(7):687-711.

9. Jeyakumar A, Brickman TM, Haben M. Effectiveness of amitriptyline versus cough suppressants in the treatment of chronic cough resulting from postviral vagal neuropathy. Laryngoscope. 2006;116(12):2108-2112.

10. Ryan NM, Birring SS, Gibson PG. Gabapentin for refractory chronic cough: a randomised, double-blind, placebo-controlled trial. Lancet. 2012;380(9853):1583-1589.

11. Vertigan AE, Kapela SL, Ryan NM, Birring SS, McElduff $P$, Gibson PG. Pregabalin and speech pathology combination therapy for refractory chronic cough: a randomized controlled trial. Chest. 2016;149(3):639-648.

12. Dicpinigaitis PV, Dobkin JB. Antitussive effect of the GABA-agonist baclofen. Chest. 1997;111(4):996-999.

13. Satia I, Badri H, Al-Sheklly B, Smith JA, Woodcock AA. Towards understanding and managing chronic cough. Clin Med (Lond). 2016;16(suppl 6):s92-s97.

14. Sasieta HC, lyer VN, Orbelo DM, et al. Bilateral thyroarytenoid botulinum toxin type $\mathrm{A}$ injection for the treatment of refractory chronic cough. JAMA Otolaryngol Head Neck Surg. 2016;142(9):881-888.

15. Ternesten-Hasséus E, Johansson EL, Millqvist E. Cough reduction using capsaicin. Respir Med. 2015;109(1):27-37.

16. Abdulqawi R, Dockry R, Holt K, et al. P2X3 receptor antagonist (AF-219) in refractory chronic cough: a randomised, double-blind, placebo-controlled phase 2 study. Lancet. 2015;385(9974):1198-1205.

\section{Disclosures}

The authors report no conflict of interest concerning the materials or methods used in this study or the findings specified in this paper.

\section{Author Contributions}

Conception and design: Morrison, Kupfer, Ford-Baldner, Kluin, HerveyJumper. Acquisition of data: Morrison, Kang, Kluin, Hervey-Jumper. Analysis and interpretation of data: Morrison, Kupfer, Ford-Baldner, Kluin, Hervey-Jumper. Drafting the article: Kang. Critically revising the article: all authors. Reviewed submitted version of manuscript: all authors. Approved the final version of the manuscript on behalf of all authors: Morrison. Study supervision: Morrison, Kupfer, Hervey-Jumper.

\section{Correspondence}

Robert J. Morrison: University of Michigan, Ann Arbor, Ml. morrisor@ med.umich.edu. 